\section{The Drosophila ortholog of vertebrate TRPA1 regulates thermotaxis}

\author{
Mark Rosenzweig, ${ }^{1}$ Karen M. Brennan, ${ }^{1}$ \\ Timothy D. Tayler, ${ }^{1}$ Paul O. Phelps, ${ }^{1}$ \\ Ardem Patapoutian, ${ }^{2,3}$ and Paul A. Garrity ${ }^{1,4}$ \\ ${ }^{1}$ Department of Biology, Massachusetts Institute of \\ Technology, Cambridge, Massachusetts 02139, USA; \\ ${ }^{2}$ Department of Cell Biology, The Scripps Research \\ Institute, La Jolla, California 92037, USA $;{ }^{3}$ Genomics \\ Institute of the Novartis Research Foundation, \\ San Diego, California 92121, USA
}

Thermotaxis is important for animal survival, but the molecular identities of temperature sensors controlling this behavior have not been determined. We demonstrate dTRPA1, a heat-activated Transient Receptor Potential (TRP) family ion channel, is essential for thermotaxis in Drosophila. $\operatorname{dTrpA1}$ knockdown eliminates avoidance of elevated temperatures along a thermal gradient. We observe dTRPA1 expression in cells without previously ascribed roles in thermosensation and implicate dTRPA1-expressing neurons in mediating thermotaxis. Our data suggest that thermotaxis relies upon neurons and molecules distinct from those required for high-temperature nociception. We propose dTRPA1 may control thermotaxis by sensing environmental temperature.

Supplemental material is available at http://www.genesdev.org.

Received November 3, 2004; revised version accepted December 21, 2004.

Animals exhibit strong behavioral responses to temperature, and many are able to thermotax, undergoing directed migration guided by differences in temperature. Central to thermotaxis are the abilities to sense environmental temperature and to execute the appropriate behavioral response. Animal thermotaxis has been studied most extensively in the nematode Caenorhabditis elegans, where ablation studies have defined the neuronal circuitry involved in thermotactic behavior and molecular genetic studies have identified several molecules required for the development and function of the thermosensory system (Mori 1999). However, the molecular identity of the thermal sensors themselves has remained unknown. Larvae and adults of the fruit fly Drosophila melanogaster also exhibit strong thermotactic behaviors (Sayeed and Benzer 1996; Zars 2001; Liu et al. 2003). No regulators of Drosophila thermotaxis have been identi-

[Keywords: Thermosensation; thermotactic behavior; dTRPAl; ANKTM1; nociception]

${ }^{4}$ Corresponding author.

E-MAIL pgarrity@mit.edu; FAX (617) 258-3128.

Article published online ahead of print. Article and publication date are at http://www.genesdev.org/cgi/doi/10.1101/gad.1278205. fied at the molecular level, and little is known of the neural circuitry that controls thermotaxis, aside from a small group of terminal organ neurons involved in larval cold avoidance (Liu et al. 2003).

Several classes of molecules have been implicated in potentially mediating temperature sensation and could be involved in thermotaxis. The two-pore-domain $\mathrm{K}^{+}$channel TREK-1 (Maingret et al. 2000) and members of the DEG/EnaC-family of $\mathrm{Na}^{+}$channels (Askwith et al. 2001) are regulated by temperature in cultured cells, while mice lacking the ATP-gated cation channel P2X3 are defective for electrophysiological responses to moderate warmth $\left(32^{\circ} \mathrm{C}-45^{\circ} \mathrm{C}\right)$ (Souslova et al. 2000). In addition, several members of the Transient Receptor Potential (TRP) family of ion channels have been shown to act as temperature-responsive ion channels in heterologous cells (Jordt et al. 2003; Patapoutian et al. 2003), and mice lacking one of these proteins, the heat-activated TRPV1, have been shown to be defective in a withdrawal response to noxious high temperature as well as thermal hyperalgesia upon inflammation (Caterina et al. 2000; Davis et al. 2000). While the mouse, C. elegans, and Drosophila melanogaster genomes all encode two-pore-domain $\mathrm{K}^{+}$channels, DEG/EnaC proteins, and TRP proteins, it has not been established whether any of these molecules play important roles in thermotaxis.

The temperature-responsive TRPs (TRPV1-V4, TRPM8, and TRPA1) have been dubbed thermoTRPs and include members of three distinct families of TRP channels: TRPV, TRPM, and TRPA (Jordt et al. 2003; Patapoutian et al. 2003). The Drosophila genome encodes two TRPV family members, one TRPM, and four TRPAs. Of these proteins, functions have been described for the TRPVs Inactive and Nanchung, which act together in hearing (Kim et al. 2003; Gong et al. 2004), and the TRPA Painless, which mediates larval nociceptive responses to high-temperature mechanical stimulation (Tracey et al. 2003). One Drosophila TRP protein has been shown to function as a temperature-responsive ion channel in heterologous cells (i.e., is a thermoTRP), dTRPA1 (formerly dANKTM1) (Viswanath et al. 2003). dTRPA1 is the Drosophila ortholog of the single mammalian TRPA protein TRPA1, and dTRPA1 opens in response to warming (Viswanath et al. 2003). However, the in vivo function of dTRPA1 (and of its mammalian ortholog) in thermosensory behavior has not been explored.

Here we develop a novel RNAi-based strategy for studying thermotactic behavior and use this approach to demonstrate that the warmth-activated ion channel dTRPA1 is essential for thermotaxis. We proceed to identify a novel group of dTRPA1-expressing neurons in the CNS that appear important for thermotactic behavior, and find that the proteins and neurons essential for thermotaxis differ from those previously implicated in high-temperature nociceptive behavior. This work identifies a candidate environmental temperature sensor for thermotaxis and provides a cellular and molecular starting point for the dissection of thermoTRP signaling and thermotaxis in Drosophila. In addition, the RNAi-based strategy described here should be applicable to the study of other behaviors in Drosophila. 


\section{Results and Discussion}

Drosophila larvae exhibit robust thermotactic behavior

We examined Drosophila thermotactic behavior by using a thermal preference assay, placing larvae on a gradient of temperatures warmer than their optimal growth temperature $\left(-24^{\circ} \mathrm{C}\right)$ (Siddiqui and Barlow 1972) and allowing the larvae to migrate from the release zone of $31^{\circ} \mathrm{C}-35^{\circ} \mathrm{C}$ into a region of even higher temperature or a region of lower temperature (Fig. 1A). Wild-type latefirst/early-second instar larvae rapidly migrated down the thermal gradient into the cooler zone (Fig. 1C; Supplementary Movie S1). Some larvae explored the warmer zone but rapidly reoriented and headed down the gradient. Larval thermotactic behavior in this thermal preference assay was quantified with an avoidance index (AI) (Fig. 1B; Liu et al. 2003). Wild-type larvae achieved AI scores $>0.9$ within 2 min (Fig. 1B), demonstrating strong heat avoidance.

\section{$\mathrm{dTrpA} 1$ is required for thermotaxis}

We devised a simple RNA interference (RNAi) strategy to survey whether any Drosophila TRPA, TRPV, or TRPM family members might contribute to larval thermotactic behavior. In this approach, embryos were injected with double-stranded RNAs (dsRNAs) corresponding to the genes of interest, and the resulting larvae were analyzed for their ability to thermotax. The injected animals contained a neuronally expressed green fluorescent protein (GFP) transgene, and dsRNA targeting GFP expression was included in all injections, serving as an in-

A

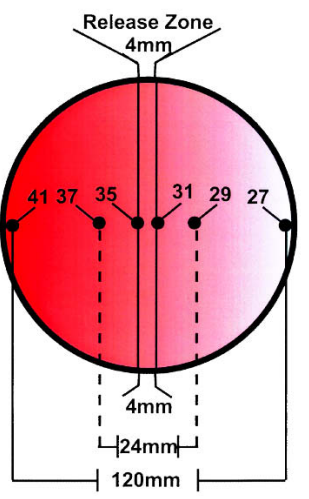

C
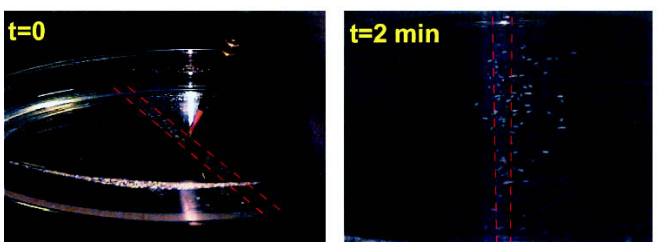

Figure 1. Thermal preference assay. $(A)$ Larvae are placed in the middle of the thermal gradient on an agarose-covered plate, within the release zone. Agar surface temperatures are as indicated. $(B)$ Larval behavior on gradient quantified by an avoidance index (AI) (Liu et al. 2003) as indicated. Graph depicts behavior of uninjected wild-type (elav-Gal4;UAS-mCD8:GFP) late-first instar/early-second instar larvae ( $n=9$ assays). (C) Still images from thermal preference assay of uninjected wild-type larvae. Red dotted lines demarcate the release zone, with heated zone at left and unheated zone at right. In all figures, data are mean \pm SEM. More than 39 larvae/assay. ternal control for a successful injection (Fig. 2A). Injection of a mixture of dsRNAs corresponding to the four TRPA family members strongly altered thermotaxis (AI scores of $<0.3$ ) (Fig. 2B). In contrast, injection of dsRNAs corresponding to the TRPVs Inactive and Nanchung or the TRPM CG30078 had no detectable effect on thermotaxis (Fig. 2B). These latter experiments served as controls demonstrating that the dsRNA injection procedure itself did not affect thermotaxis. Taken together, our data suggest that one or more Drosophila TRPA family members is required for thermotaxis.

Strikingly, RNAi of $d \operatorname{Trp} A 1$ alone strongly disrupted avoidance of elevated temperature. Unlike wild-type larvae, similar numbers of $d \operatorname{Trp} A 1$ (RNAi) larvae migrated into both warmer and cooler zones, yielding AI scores near zero (Fig. 2D), and many $d \operatorname{Trp} A 1$ (RNAi) larvae traveled deep into the warmer area (Fig. 2C; Supplementary Movie S2). Injection of dsRNA against a second, nonoverlapping region of $d \operatorname{Trp} A 1$ also generated AI scores near zero (Fig. 2D). $d \operatorname{Trp} A 1$ knockdown disrupted thermotactic behavior throughout larval life, as third instar $d \operatorname{Trp} A 1(R N A i)$ larvae also exhibited thermotaxis defects (Fig. 2E). Injection of dsRNAs against the three other TrpAs had no effect on thermotaxis (Fig. 2D). We further examined the TRPA Painless, which mediates responses to high-temperature mechanical stimulation (Tracey et al. 2003), a thermosensory behavior potentially distinct from thermotaxis. Neither late-first instar/early-second instar nor third instar painless mutant larvae (pain ${ }^{1}$ and pain $\left.^{3}\right)$ were defective for thermotaxis in our assay (Fig. 2D,E). Our data demonstrate that $d \operatorname{Trp} A 1$ is absolutely required for proper behavior in the thermal preference assay, providing strong genetic evidence for $d \operatorname{Trp} A 1$ involvement in thermotaxis. Furthermore, these data also suggest that the TRPA proteins Painless and dTRPAl have distinct roles in temperature-regulated behavior.

\section{dTrpA1(RNAi) larvae are selectively defective for thermotactic behavior}

We next tested how specific the behavioral defect of $d \operatorname{Trp} A 1$ (RNAi) animals was for thermotaxis. First, we determined that the motility indices (MIs) of wild-type and $d \operatorname{Trp} A 1$ (RNAi) larvae in the thermal gradient were indistinguishable. (The MI represents the fraction of larvae no longer in the release zone at a given time point [see Materials and Methods].) Latefirst instar/early-second instar wild-type larvae had MIs of $0.56 \pm 0.08$ and $0.64 \pm 0.08$ at 2 and $5 \mathrm{~min}$ after release $(n=9$ assays, \pm SEM), while $d \operatorname{Trp} A 1(R N A i)$ larvae had MIs of $0.60 \pm 0.06$ and $0.69 \pm 0.04$ at these time points ( $n=11$ assays). Thus $d \operatorname{Trp} A 1$ (RNAi) animals were specifically defective in thermotaxis rather than in their ability to migrate at elevated temperature. Second, we examined larval chemotaxis in response to an olfactory repellent (n-octyl acetate) (Heimbeck et al. 1999), and found $d \operatorname{Trp} A 1$ (RNAi) larvae responded similarly to wild type (Fig. 3A), indicating that $d \operatorname{Trp} A 1(R N A i)$ larvae were not defective for all avoidance behavior. Finally, we examined responsiveness of $d \operatorname{Trp} A 1(R N A \mathrm{i})$ 
A

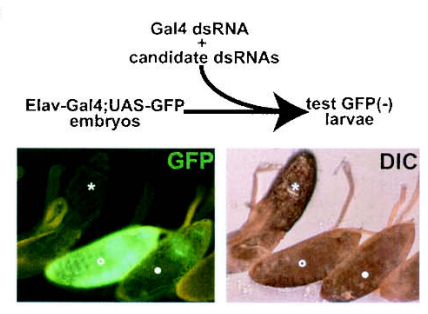

B

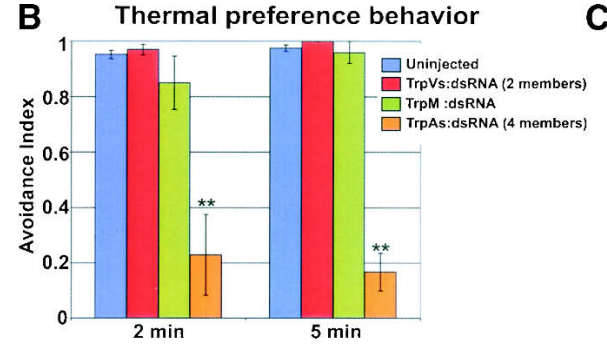

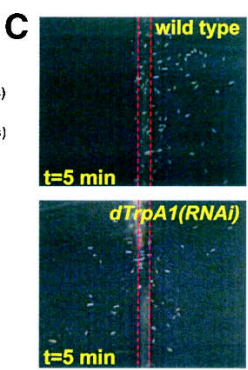

D

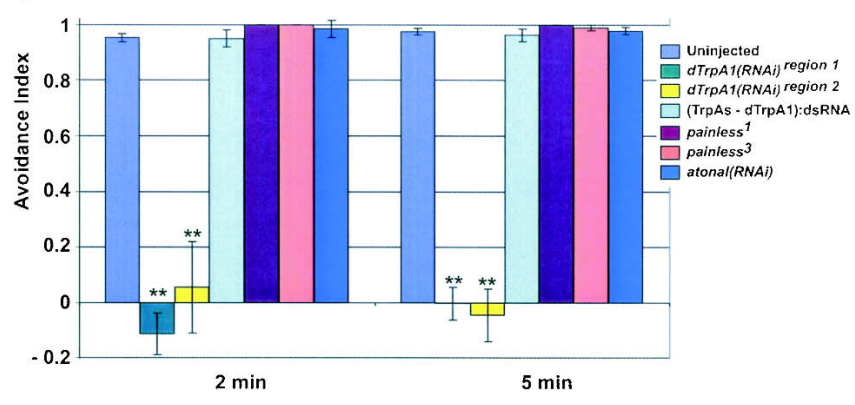

E Thermal preference behavior (third instar)

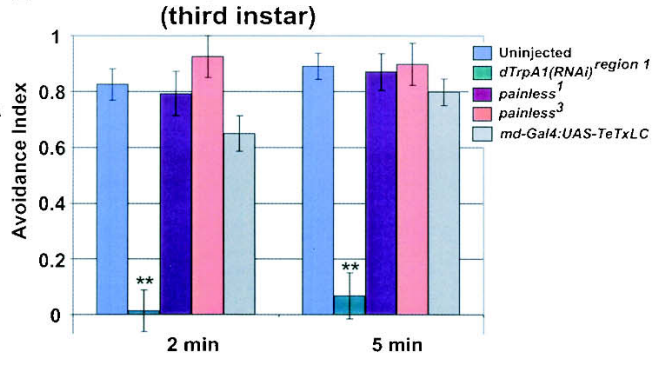

Figure 2. $d \operatorname{Trp} A 1$ is required for thermosensory behavior. (A) RNAi strategy (methods). GFP-negative (asterisk), but not GFP-positive (circles), RNAi animals were retained for analysis. (B) Late-first/early-second instar behavior. Uninjected ( $n=9$ assays); TrpVs:dsRNA, injected with Gal4, Inactive, and Nanchung dsRNAs (Gal4 + Inactive + Nanchung) $(n=4)$; TrpM:dsRNA:Gal4 + CG30078 ( $n=4)$; TrpAs:dsRNA:Gal4 + dTrpA1 + Painless + CG17142 + CG31284 (n=6). (C) Preference assay (orientation as in Fig. 1C). (D) As in B except $d$ TrpA1(RNAi)region 1 : Gal4 + dTrpA1(region 1) $(n=7)$. dTrpA1(RNAi) region ${ }^{2}:$ Gal4 + dTrpA1(region 2) $(n=4) ;$ TrpAs-dTrpA1:dsRNA:Gal4 + Painless + CG17142 + CG31284 $(n=4)$; painless ${ }^{1}(n=5)$; painless $^{3}(n=4)$; atonal $(R N A i)(n=4)$. $(E)$ Third instar behavior. Uninjected $(n=9)$; $d$ TrpA1(RNAi)region 1 $(n=13)$; painless $^{1}(n=7)$; painless ${ }^{3}(n=4)$; md-Gal4:UAS-TeTxLC $(n=12)$. $\left.{ }^{\star \star}\right) p<0.0001$ (versus uninjected). Slight md-Gal4:UAS-TeTxLC effect was not statistically significant ( $p=0.09,2 \mathrm{~min} ; p=0.27,5 \mathrm{~min}$ ) and may reflect their noted uncoordination (Tracey et al. 2003). Nineteen to 75 larvae/assay.

larvae to higher temperatures $\left(55^{\circ} \mathrm{C}\right)$. Because larvae rapidly died when exposed to gradients of higher temperature (data not shown), larvae were tested by using a previously described temperature-dependent nociceptive assay (Tracey et al. 2003). Crawling third instar larvae rapidly and dramatically curl when touched with a hot $\left(55^{\circ} \mathrm{C}\right)$ probe $($ Fig. $3 \mathrm{~B})$ but not when touched with a $25^{\circ} \mathrm{C}$ or $36^{\circ} \mathrm{C}$ probe. $d \operatorname{Trp} A 1$ (RNAi) larvae responded indistinguishably from wild-type larvae in this assay (Fig. 3B,C). As a negative control for the assay, we examined larvae expressing tetanus toxin light chain (TeTxLC), an inhibitor of synaptic vesicle release (Sweeney et al. 1995), under md-Gal4 (Gao et al. 1999) control (md-Gal4 is expressed in multiple-dendritic neurons and $100 \mathrm{CNS}$ neurons) (Tracey et al. 2003). As previously reported (Tracey et al. 2003), md-Gal4:UAS-TeTxLC larvae were defective in response to contact with the hot probe (Fig. $3 \mathrm{C})$. The ability of $d \operatorname{Trp} A 1(R N A i)$ larvae to chemotax and respond to other thermal stimuli suggests a specific requirement for $d \operatorname{Trp} A 1$ in thermotaxis.

\section{dTRPA1 expression and the role of dTrpA1-Gal4-expressing cells in thermosensation}

Antisera raised against dTRPA1 detected strong dTRPA1 protein expression in a small number of central brain neurons (Fig. 4A,B) and in neuroendocrine cells of the corpus cardiacum (Fig. 4A). $d \operatorname{TrpA1}$ (RNAi) larvae had no detectable dTRPA1 expression in these regions, demonstrating that our antisera was specific for dTRPA1 and that the $d \operatorname{Trp} A 1$ dsRNA effectively reduced dTRPA1 protein expression (Fig. 4C). Specific dTRPA1 expression was also detected in two pairs of cells adjacent to the mouthhooks and in the developing gut (data not shown). Interestingly, we did not detect dTRPA1 expression in either multiple-dendritic neurons (implicated in temperature-dependent nociceptive responses) (Tracey et al. 2003) or chordotonal neurons, both of which show temperature-dependent calcium changes (Liu et al. 2003). We explored the role of multiple-dendritic neurons using md-Gal4:UAS-TeTxLC larvae. Consistent with no significant role of multiple-dendritic neurons in our thermotaxis assay, significant thermotaxis defects were not detected in md-Gal4:UAS-TeTxLC larvae (Fig. 2E). In addition, significant thermotaxis defects were not detected in atonal(RNAi) larvae, which lack chordotonal neurons (Fig. 2D; Huang et al. 2000; see Materials and Methods). These data suggest that there may be differences in the neuronal circuitry required for thermotaxis in response to elevated temperature and withdrawal from a hightemperature nociceptive stimulus.

The role of dTRPA1-expressing cells in thermotaxis was further examined by expressing TeTxLC or the cell death-promoting gene Hid under control of putative $d \operatorname{Trp} A 1$ promoter sequences. $d \operatorname{Trp} A 1-$ Gal4 drove GFP expression in most dTRPAl-expressing central brain neurons (Fig. 4D-F), but not in the other dTRPA1-expressing cell populations (data not shown). dTrpA1Gal4:UAS-Hid animals had reduced numbers of dTRPA1-expressing brain neurons (e.g., only one of the three dTPRA1-expressing cells in Fig. 4D-F was present), while the corpus caridiaca appeared unaffected (see $\mathrm{Ma}$ terials and Methods). Consistent with the participation of $d \operatorname{TrpA1-Gal4-expressing~cells~in~thermosensory~be-~}$ 

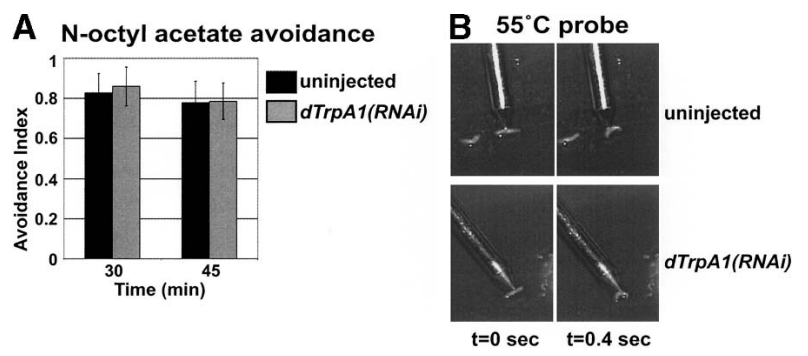

C

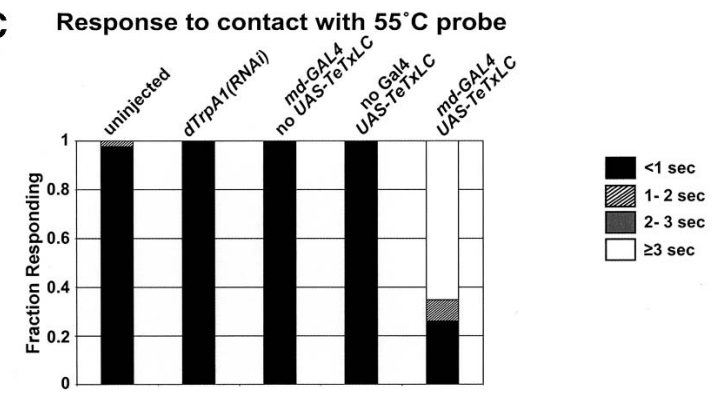

Figure 3. $d \operatorname{Trp} A 1(R N A i)$ animals respond to other stimuli. $(A) \mathrm{n}$ Octyl acetate avoidance of late-first/early-second instar elavGal4;UAS-mCD8:GFP larvae, uninjected, or $d T r p A 1$ (RNAi) (region 1) $(n=6$ assays for each). Odor avoidance $=[$ (number of larvae in no odorant zone) - (number of larvae in odorant zone)]/[(number of larvae in no odorant zone) + (number of larvae in odorant zone)]. $(B)$ Response to contact with $\sim 55^{\circ} \mathrm{C}$ probe of third instar uninjected and $d \operatorname{Trp} A 1(R N A i)$ larvae. $(C)$ Time between probe contact and initiation of curling. Uninjected $\left(n=41\right.$ larvae); $\operatorname{dTr} A 1(R N A i)^{\text {region } 1}$ $(n=24)$; md-Gal4 $(n=23)$; UAS-TeTxLC $(n=30)$; md-Gal4:UASTeTxLC $(n=23)$. Most larvae not responding within $3 \mathrm{sec}$ never exhibited detectable curling.

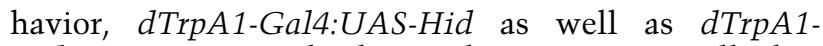
Gal4:UAS-TeTxLC third instar larvae were partially, but significantly $(p<0.005)$, compromised in thermotactic behavior (Fig. 4G).

Interestingly, both $d \operatorname{Trp} A 1$ Gal4:UAS-TeTxLC and $\operatorname{TTrpA1-}$ Gal4:UAS-Hid larvae exhibited normal withdrawal from a high-temperature nociceptive stimulus (Fig. 4H), indicating that these animals were not defective for all thermosensory responses. Similar effects were also obtained using a second, independent dTrpA1-Gal4 insertion (data not shown). These data further support the notion that there may be differences in the neuronal circuitry required for thermotaxis and high-temperature nociception.

\section{dTRPA1 is an essential regulator of thermotaxis}

The ability to move toward favorable environmental temperatures and away from unfavorable environmental temperatures is critical for animal survival. While thermotactic behavior has been observed in many animals, the underlying thermal sensors have not been identified. Here we have used the heat-avoidance re- sponse of Drosophila larvae to identify $d \operatorname{Trp} A 1$ as a key mediator of thermotaxis. The failure of animals lacking dTRPA1 expression to avoid elevated temperatures mirrors the ability of dTRPA1 to function as a heat-activated ion channel in vitro. Taken together, these data make dTRPA1 an attractive candidate for an environmental temperature sensor controlling thermotaxis. It will be of interest to explore how the temperature-sensing properties of dTRPA1 observed in cultured cells relate to the physiological and behavioral responses of the intact animal. As closely related dTRPA1 orthologs are present in the Drosophila pseudoobscura, Bombyx morii, and Anopheles gambiae genomes, as well as the C. elegans genome, TRPA1s could regulate thermotaxis in other insects as well as in C. elegans.

\section{Thermotaxis and high-temperature nociception involve distinct mechanisms}

Another Drosophila TRPA protein, Painless, also modulates thermosensory behavior (Tracey et al. 2003). However, dTRPA1 and Painless appear to have distinct thermosensory functions. While painless mutant larvae are strongly defective in responding to noxious high-temperature mechanical stimulation (Tracey et al. 2003), painless mutants are normal in our thermotaxis assays. Further emphasizing the apparent differences between these different thermosensory behaviors, inhibition of the md-Gal4-expressing neurons disrupts responses to noxious high-temperature mechanical stimulation but has no significant effect on thermotaxis, while inhibi-

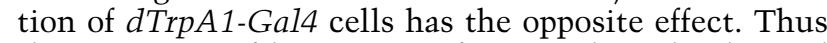
the migration of larvae away from moderately elevated temperatures (thermotaxis) and the high-temperature nociceptive response appear to rely upon distinct TRPAfamily members and potentially distinct neural circuits.
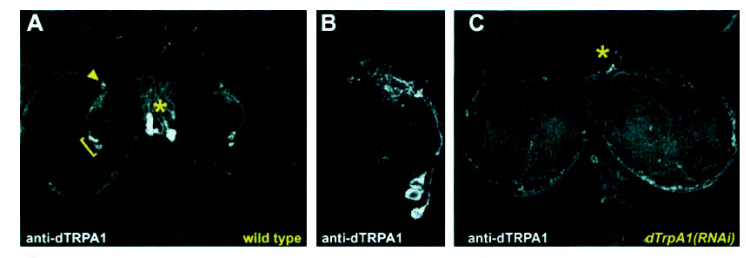

G

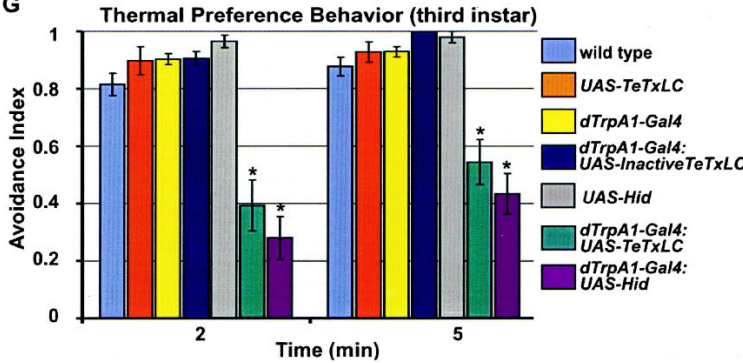

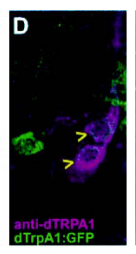
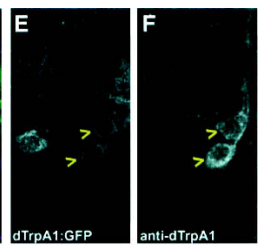

H Response to $55^{\circ} \mathrm{C}$ probe

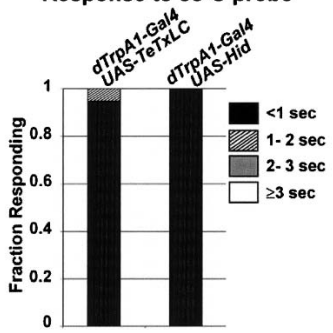

Figure 4. dTRPA1 expression. (A) dTRPAl expression in anterior (arrowhead) and posterior (bracket) groups of neurons within the brain and in neuroendocrine cells of corpus cardiacum (asterisk). (B) Posterior group of dTRPA1-expressing neurons. (C) $d \operatorname{Trp} A 1$ (RNAi) animals lack dTRPA1 staining. Asterisk denotes corpus cardiacum. (D-F) dTrpA-Gal4:UAS-mCD8:GFP (green) expression. $d$ TrpA1-Gal4 drives GFP expression in dTRPA1-expressing (purple) neurons and 100-150 additional cells within the brain. $(E)$ GFP. $(F)$ Anti-dTRPA1. (G) Thermal preference behavior. Wild type $(n=9$ assays); UAS-TeTxLC $(n=8) ; d \operatorname{TrpA1-Gal4}(n=9)$; dTrpA1-Gal4:UAS-InactiveTeTxLC $(n=6) ;$ UAS-Hid $(n=6) ; \quad d T r p A 1-G a 14: U A S-T e T x L C$ $(n=10) ; d \operatorname{TrpA1-Ga14:UAS-Hid~}(n=10) .\left({ }^{\star}\right) p<0.005$. $(H)$ Response to $\sim 55^{\circ} \mathrm{C}$ probe contact. dTrpA1-Gal4:UAS-TeTxLC $(n=19)$; dTrpA1-Gal4:UAS-Hid $(n=20)$. 
Determining the neuronal circuitry required for $d \operatorname{Trp} A 1$-dependent thermotaxis is an important goal for the future. Our $d \operatorname{TrpA1-Gal4-mediated~inhibition~and~}$ ablation studies are consistent with a role for dTRPA1expressing CNS neurons in $d \operatorname{Trp} A 1$-dependent thermotaxis. CNS thermal sensors have been proposed within the head and thoracic ganglia of adult bees and cockroaches (Heinrich 1980, 1993; Murphy and Heath 1983) and are found in the vertebrate preoptic-anterior hypothalamus (Boulant 2000). As small insects (Drosophila larvae are $<5 \mathrm{mg}$ ) have limited heat capacity (Stevenson 1985; Heinrich 1993), internal sensors of elevated temperature could be quite effective. Most importantly, identification of dTRPAl-expressing cells provides an entry point into defining the neuronal circuitry controlling thermotaxis in flies. It will be of interest to determine how dTRPA1-expressing cells participate in the sensation of environmental temperature, either as primary thermosensory cells or as higher-order neurons involved in processing thermosensory input.

dTRPA1 could have functions in addition to thermotaxis. The strong expression of dTRPA1 in the corpus cardiacum is intriguing as this neuroendocrine gland is involved in temperature-dependent developmental phenomena in some insects, including seasonal polyphenism in butterfly wings, where corpus cardiacum ablation prevents establishment of the summer wing pattern (Fukuda and Endo 1966). Furthermore, vertebrate TRPA1 has been proposed as a candidate mechanotransduction channel for hearing (Corey et al. 2004). Whether dTRPA1 responds to mechanical stimulation is unknown, but future analysis of dTRPA1 function in flies could potentially yield insights into mechanosensation as well as thermosensation.

\section{Materials and methods}

Molecular genetics and RNAi

Fly strains were obtained from Bloomington, except for painless ${ }^{1}$ and painless $^{3}$ from the EP collection (Exelixis) (Rorth et al. 1998), md-Gal4 (Gao et al. 1999) from Y. Jan (University of California, San Francisco, San Francisco, CA), UAS-TeTxLC (UAS-TNT-C) (Sweeney et al. 1995) from Troy Littleton (Massachusetts Institute of Technology, Cambridge, MA), and UAS-Hid(\#14) from Hermann Steller (Rockefeller University, New York, NY). RNAi was performed as described (Sears et al. 2003), except the concentration of each dsRNA in injection mixtures was from 1.3 $\mathrm{mg} / \mathrm{mL}$ for mixtures of five dsRNAs up to $5 \mathrm{mg} / \mathrm{mL}$ for mixtures of two dsRNAs. Injections were into elav-Gal4;UAS-mCD8:GFP animals, and Gal4 dsRNA was included in each injection mix. Thirteen to $24 \mathrm{~h}$ after injection, animals with unaltered (Fig. 2A, open circle) or partially diminished GFP expression (Fig. 2A, closed circle) were eliminated (they comprised $\sim 2 \%-3 \%$ and $<20 \%$ of total injected animals, respectively). Animals lacking GFP expression were grown on molasses plates at $25^{\circ} \mathrm{C}$. On day 3 (injected day 0), late-first/early-second instar larvae (approximately the size of 48-h-old uninjected elav-Gal4;UAS-mCD8:GFP larvae) were used in analyses. Following the assay, larvae were allowed to recover on molasses plates overnight at $25^{\circ} \mathrm{C}$; larvae significantly larger than 48 -h elav-Gal4; UAS-mCD8:GFP larvae were removed and the rest assayed once more. Larvae were then allowed to develop to third instar for further analysis. dTrpAl dsRNAs corresponded to bases 1241-1787 (region 1) and 2872-3605 (region 2) of dTRPA1 cDNA (AY302598) (Viswanath et al. 2003). Details of all dsRNAs are provided in the Supplemental Material. Chordotonal neuron loss in atonal(RNAi) larvae was confirmed by examining elav-Gal4;UAS-mCD8:GFP in animals injected with only Atonal dsRNA. dTrpA1-Gal4 was created by cloning 33-1301 bp upstream of the dTRPA1 translational start into pGATB (Brand and Perrimon 1993). dTrpA1-Ga14:UAS-mCD8:GFP expression in both lines used did not overlap with $d \operatorname{Trp} A 1$ protein expression in the larval anterior, gut, or corpus cardiaca. Both $d \operatorname{TrpA1-Ga14}$ lines drove expression in small but nonoverlapping populations of peripheral neurons.
Antibody production and histology

Rat polyclonal dTRPA1 antiserum was raised (Covance) against the 178 C-terminal amino acids of $d \operatorname{Trp} A 1$ fused to 6XHis. dTRPAl staining of neurons in larval brain and corpus cardiacum was initially detected at first instar and persisted until third instar. Expression of a $d \operatorname{Trp} A 1 \mathrm{cDNA}$ in the retina resulted in robust ectopic staining and permitted detection of dTRPA1 protein by Western blot (Supplementary Fig. 1). Images were obtained using a Nikon PCM2000 confocal microscope and Zeiss Axioplan2 with Nikon DXM1200 camera.

\section{Behavioral assays}

Thermal gradient assay was similar in design to that of Liu et al. (2003), but with different temperatures. Thermal gradient assay was performed on $2 \%$ agarose $(25 \mathrm{~mL}$ ) in a $150 \times 15 \mathrm{~mm}$ Petri dish (VWR 25384-139) placed so that the release zone was at the interface of two metal slide warmers (one heated to $\sim 47^{\circ} \mathrm{C}$, one unheated) $4 \mathrm{~mm}$ apart. Agarose surface was allowed to equilibrate for $\geq 50 \mathrm{~min}$ prior to each assay (with dish lid in place). Surface temperatures were determined using a Fluke 52II thermometer with dual K-type flat surface probes. Larvae were washed in distilled water and lined up in the release zone with a paint brush. Plate was immediately covered with a lid $(t=0)$. Larvae were raised on molasses plates or in bottles and vials with food. Larvae expressing TeTxLC or Hid were examined at third instar to permit maximum TeTxLC or Hid accumulation. Hid ablation of dTRPAl cells was quantified using the three large dTRPA1-expressing CNS neurons bracketed in Figure 4. Three cells were observed in all $10 d \operatorname{TrpA1-Gal4:UAS-GFP}$ hemispheres and all eight UAS-Hid hemispheres examined, while one cell was ob-

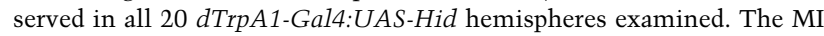
represented the fraction of larvae no longer in the release zone at a given time point. $\mathrm{MI}=$ (number of larvae in cooler zone + number of larvae in warmer zone)/(total number of larvae). All statistical comparisons used two-tailed unpaired $t$-test versus uninjected.

Animals expressing active toxins exhibited modest reductions in MI. MI of third instar dTrpA1-Ga14;UAS-TeTxLC larvae were $0.57 \pm 0.04$ and $0.69 \pm 0.03$ at 2 and $5 \mathrm{~min}(n=10$ assays $)$ and those of $d T r p A 1-$ Gall:UASHid larvae were $0.70 \pm 0.05$ and $0.78 \pm 0.04(n=10)$, while those of wildtype larvae were $0.86 \pm 0.03$ and $0.89 \pm 0.02(n=10)$. However, the value of the MI did not correlate with thermotaxis defects, suggesting the reduced MI is not the source of the thermotaxis defect. dTrpA1-Gal4:UASHid animals had a higher MI than did dTrpA1-Gal4:UAS-TeTxLC animals, but were more defective for thermotaxis. Furthermore, the dTrpA1-Gal4:UAS-Hid MI was not significantly different from that of md-Gal4:UAS-TeTxLC $(0.75 \pm 0.05$ and $0.85 \pm 0.03 ; n=12)$, but thermotaxis in $d T r p A 1-G a 14: U A S$-Hid was substantially reduced compared with that in md-Gal4:UAS-TeTxLC $(p<0.002)$. In addition, third instar dTrpA1-Ga14 and dTrpA1-Ga14:UAS-Hid larvae performed indistinguishably for chemotaxis, with n-octyl acetate AIs of $0.67 \pm 0.07$ and $0.66 \pm 0.09$, respectively ( $n=6$ assays for each, 60 -min time point), suggesting a specific defect in thermotaxis.

Probe assay was performed using a Sears Craftsman Soldering Iron (113.540410) controlled by a Statco Variac (3P1V221B). Probe temperature was monitored with Physitemp BAT-12 thermometer equipped with $\mathrm{K}$-type flat surface probe and varied between $55^{\circ} \mathrm{C}$ and $57^{\circ} \mathrm{C}$ during assays. The Supplementary Movies were made with a Sony TRV38 and edited with Apple iMovie. Odor avoidance assays were performed as described (Heimbeck et al. 1999), except $2.5 \mu \mathrm{L}$ of undiluted n-octyl acetate (Sigma) was presented in microcentrifuge tube cap opposite an empty cap, and late-first/early-second instar larvae were assayed for uninjected and $d \operatorname{Trp} A 1(R N A i)$.

\section{Acknowledgments}

We thank Y. Jan and T. Littleton for fly strains; T. Jegla, G. Story, and V. Viswanath for helpful discussions and communicating results prior to publication; L. Guarente, H.R. Horvitz, R. Huey, R. Hynes, T. OrrWeaver, C. Quinn, W. Rhyu, R. Stevenson, D. Tracey, B. Wold, and Garrity lab members for helpful discussions; S. Gilbert, F. Nijhout, and R. Stevenson for reprints; and A. Chess, L. Huang, R. Huey, R. Khodosh, J. Whited, and B. Wold for comments on the manuscript. This work was supported by a grant to P.A.G. from the Raymond and Beverly Sackler Foundation and a Whitehead Family Career Development Professorship. M.R. was supported by an NSF Graduate Research Fellowship and an NIH Predoctoral Training Grant, and T.D.T. was supported by an NIH Predoctoral Training Grant. 


\section{References}

Askwith, C.C., Benson, C.J., Welsh, M.J., and Snyder, P.M. 2001. DEG/ $\mathrm{ENaC}$ ion channels involved in sensory transduction are modulated by cold temperature. Proc. Natl. Acad. Sci. 98: 6459-6463.

Boulant, J.A. 2000. Role of the preoptic-anterior hypothalamus in thermoregulation and fever. Clin. Infect. Dis. 31(Suppl 5): S157-S161.

Brand, A.H. and Perrimon, N. 1993. Targeted gene expression as a means of altering cell fates and generating dominant phenotypes. Development 118: 401-415.

Caterina, M.J., Leffler, A., Malmberg, A.B., Martin, W.J., Trafton, J., Petersen-Zeitz, K.R., Koltzenburg, M., Basbaum, A.I., and Julius, D. 2000. Impaired nociception and pain sensation in mice lacking the capsaicin receptor. Science 288: 306-313.

Corey, D.P., Garcia-Anoveros, J., Holt, J.R., Kwan, K.Y., Lin, S.Y., Vollrath, M.A., Amalfitano, A., Cheung, E.L., Derfler, B.H., Duggan, A., et al. 2004. TRPA1 is a candidate for the mechanosensitive transduction channel of vertebrate hair cells. Nature 432: 723-730

Davis, J.B., Gray, J., Gunthorpe, M.J., Hatcher, J.P., Davey, P.T., Overend, P., Harries, M.H., Latcham, J., Clapham, C., Atkinson, K., et al. 2000. Vanilloid receptor-1 is essential for inflammatory thermal hyperalgesia. Nature 405: 183-187.

Fukuda, S. and Endo, K. 1966. Hormonal control of the development of seasonal forms in the butterfly Polygonia c-aureum. Proc. Japan. Acad. 42: 1082-1087.

Gao, F.B., Brenman, J.E., Jan, L.Y., and Jan, Y.N. 1999. Genes regulating dendritic outgrowth, branching, and routing in Drosophila. Genes \& Dev. 13: 2549-2561.

Gong, Z., Son, W., Chung, Y.D., Kim, J., Shin, D.W., McClung, C.A., Lee, Y., Lee, H.W., Chang, D.J., Kaang, B.K., et al. 2004. Two interdependent TRPV channel subunits, inactive and Nanchung, mediate hearing in Drosophila. J. Neurosci. 24: 9059-9066.

Heimbeck, G., Bugnon, V., Gendre, N., Haberlin, C., and Stocker, R.F. 1999. Smell and taste perception in Drosophila melanogaster larva: Toxin expression studies in chemosensory neurons. J. Neurosci. 19: 6599-6609.

Heinrich, B. 1980. Mechanisms of body temperature regulation in honeybees, Apis mellifera. J. Exp. Biol. 85: 61-72.

- 1993. The hot-blooded insects: Strategies and mechanisms of thermoregulation. Harvard University Press, Boston, MA.

Huang, M.L., Hsu, C.H., and Chien, C.T. 2000. The proneural gene amos promotes multiple dendritic neuron formation in the Drosophila peripheral nervous system. Neuron 25: 57-67.

Jordt, S.E., McKemy, D.D., and Julius, D. 2003. Lessons from peppers and peppermint: The molecular logic of thermosensation. Curr. Opin. Neurobiol. 13: 487-492.

Kim, J., Chung, Y.D., Park, D.Y., Choi, S., Shin, D.W., Soh, H., Lee, H.W., Son, W., Yim, J., Park, C.S., et al. 2003. A TRPV family ion channel required for hearing in Drosophila. Nature 424: 81-84.

Liu, L., Yermolaieva, O., Johnson, W.A., Abboud, F.M., and Welsh, M.J. 2003. Identification and function of thermosensory neurons in Drosophila larvae. Nat. Neurosci. 6: 267-273.

Maingret, F., Lauritzen, I., Patel, A.J., Heurteaux, C., Reyes, R., Lesage, F., Lazdunski, M., and Honore, E. 2000. TREK-1 is a heat-activated background $\mathrm{K}(+)$ channel. EMBO J. 19: 2483-2491.

Mori, I. 1999. Genetics of chemotaxis and thermotaxis in the nematode Caenorhabditis elegans. Annu. Rev. Genet. 33: 399-422.

Murphy Jr., B.F. and Heath, J.E. 1983. Temperature sensitivity in the prothoracic ganglion of the cockroach, Periplaneta americana, and its relationship to thermoregulation. J. Exp. Biol. 105: 305-315.

Patapoutian, A., Peier, A.M., Story, G.M., and Viswanath, V. 2003. ThermoTRP channels and beyond: Mechanisms of temperature sensation. Nat. Rev. Neurosci. 4: 529-539.

Rorth, P., Szabo, K., Bailey, A., Laverty, T., Rehm, J., Rubin, G.M., Weigmann, K., Milan, M., Benes, V., Ansorge, W., et al. 1998. Systematic gain-of-function genetics in Drosophila. Development 125: 10491057.

Sayeed, O. and Benzer, S. 1996. Behavioral genetics of thermosensation and hygrosensation in Drosophila. Proc. Nat1. Acad. Sci. 93: 60796084.

Sears, H.C., Kennedy, C.J., and Garrity, P.A. 2003. Macrophage-mediated corpse engulfment is required for normal Drosophila CNS morphogenesis. Development 130: 3557-3565.
Siddiqui, W.H. and Barlow, C.A. 1972. Population growth of Drosophila melanogaster (Dipetera: Drosophilidae) at constant and alternating temperatures. Ann. Entomol. Soc. Am. 65: 993-1001.

Souslova, V., Cesare, P., Ding, Y., Akopian, A.N., Stanfa, L., Suzuki, R., Carpenter, K., Dickenson, A., Boyce, S., Hill, R., et al. 2000. Warmcoding deficits and aberrant inflammatory pain in mice lacking P2X3 receptors. Nature 407: 1015-1017.

Stevenson, R.D. 1985. Body size and limits to the daily range of body temperature in terrestrial ectotherms. Am. Nat. 125: 102-117.

Sweeney, S.T., Broadie, K., Keane, J., Niemann, H., and O'Kane, C.J. 1995. Targeted expression of tetanus toxin light chain in Drosophila specifically eliminates synaptic transmission and causes behavioral defects. Neuron 14: 341-351.

Tracey Jr., W.D., Wilson, R.I., Laurent, G., and Benzer, S. 2003. painless, a Drosophila gene essential for nociception. Cell 113: 261-273.

Viswanath, V., Story, G.M., Peier, A.M., Petrus, M.J., Lee, V.M., Hwang, S.W., Patapoutian, A., and Jegla, T. 2003. Opposite thermosensor in fruitfly and mouse. Nature 423: 822-823.

Zars, T. 2001. Two thermosensors in Drosophila have different behavioral functions. J. Comp. Physiol. A 187: 235-242. 


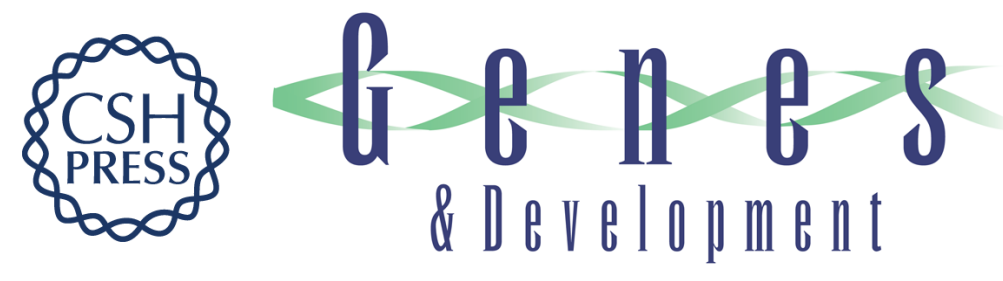

\section{The Drosophila ortholog of vertebrate TRPA1 regulates thermotaxis}

Mark Rosenzweig, Karen M. Brennan, Timothy D. Tayler, et al.

Genes Dev. 2005, 19:

Access the most recent version at doi:10.1101/gad.1278205

Supplemental

Material

References

This article cites 28 articles, 12 of which can be accessed free at: http://genesdev.cshlp.org/content/19/4/419.full.html\#ref-list-1

\section{License}

Email Alerting Service

http://genesdev.cshlp.org/content/suppl/2005/01/25/gad.1278205.DC1 right corner of the article or click here.

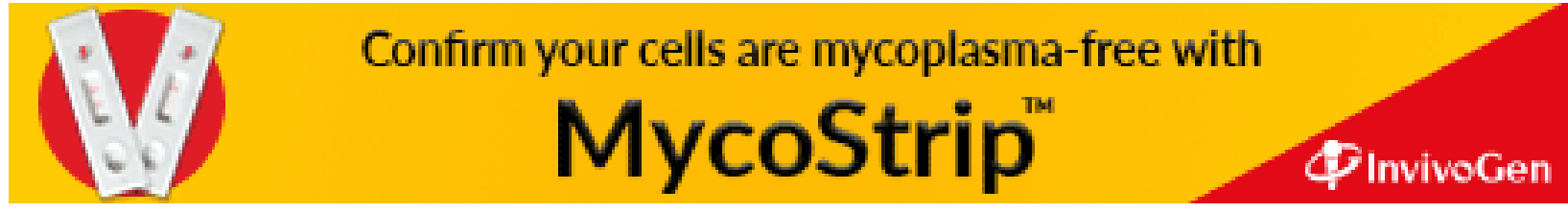

